\title{
Protrusions designs of AFRP to eliminate slippage of bonding adhesive
}

Khalid Abdel Naser Abdel Rahim

Department of Civil Engineering, Faculty of Science and Technology, University of Coimbra, Rua Luis Reis dos Santos 290, 3030-790 Coimbra, Portugal.

A presentation of a new innovative smart designs of protrusions in Aramid Fiber Reinforced Polymer (AFRP) which could lead the manufacturing industry of AFRP to a new era. The classic straight AFRP strips has a major disadvantage when externally bonded with other engineering materials using bonding adhesive. When exposed to high temperatures, the bonding adhesive slides causing a weak bondage or a complete debonding in some cases between the AFRP and engineering material surfaces. Thus, the purpose of protrusions in AFRP laminates is to eliminate the slippage of the bonding adhesive between the AFRP strips and other engineering material surfaces. This takes place by eliminating the frictional factor between the surfaces of AFRP laminate and bonded engineering material.

Mainly three protrusions shapes were used to initiate the designed catalogue. These are squared, triangular and semitriangular protrusions, as shown in figures 1,2 and 6 respectively. Two types of designs where used for the triangular protrusions. For example, spaced and continuous designs as illustrated in figures 2 and 5 respectively. In addition, two different geometrical protrusions were combined in some designs to produce a two geometrical composite designs. For instance, (a) squared and triangular in figure 3, (b) triangular and semi-triangular in figure 4 , (c) rectangular and semitriangular in figure 7 , (d) squared and semi-triangular in figure 8. Furthermore, two designs were used for composite triangular and semitriangular protrusions. These are spaced and continuous as presented in figures 4 and 9 respectively.

This catalogue poster protrusions designs of AFRP can be extended to produce further advanced triple composite protrusions designs. Such as, composite squared, triangular and semitriangular protrusions design of an AFRP laminate.
Figure 1. Squared protrusions design of an AFRP laminate.

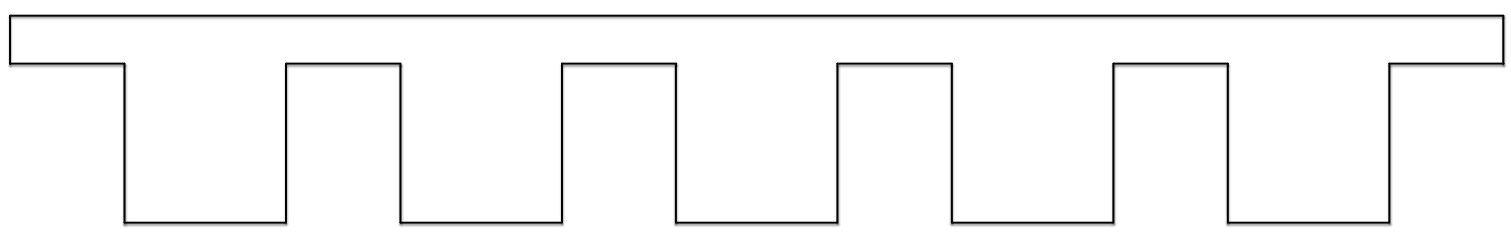

Figure 2. Spaced triangular protrusions design of an AFRP laminate.

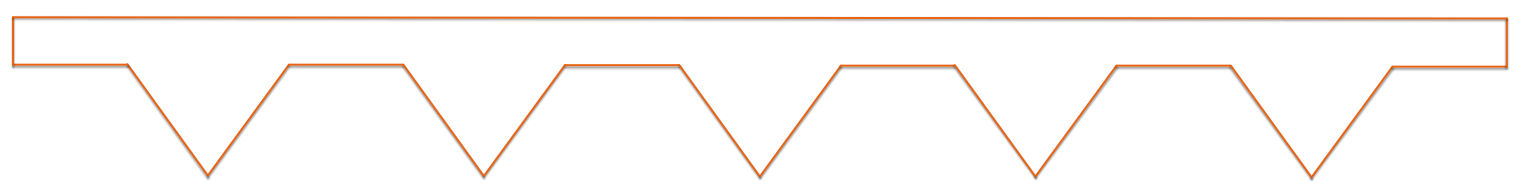

Figure 3. Composite squared and triangular protrusions design of an AFRP laminate.

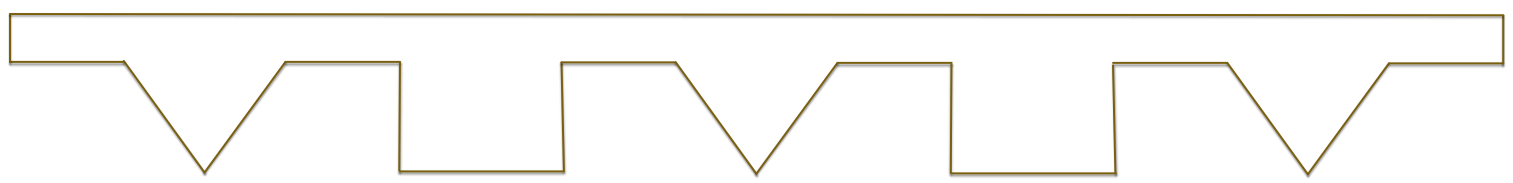

Figure 4. Spaced Composite triangular and semi-triangular protrusions design of an AFRP laminate.

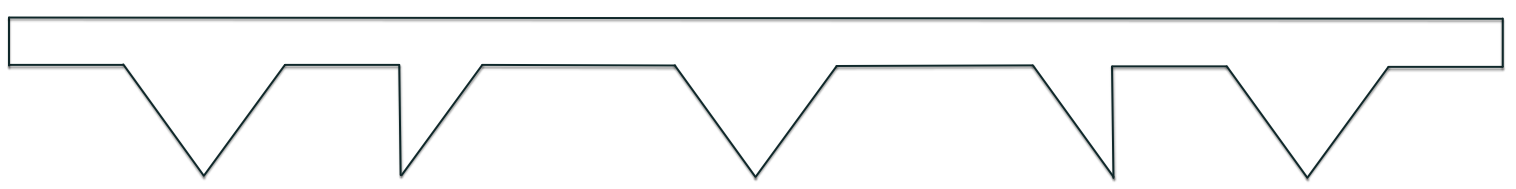

Figure 5. Continuous triangular protrusions design of an AFRP laminate.

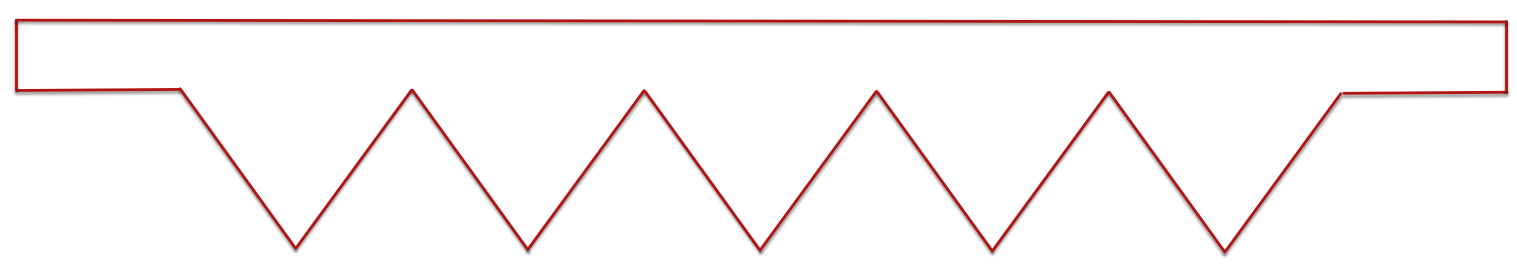

Figure 6. Semi-triangular protrusions design of an AFRP laminate.

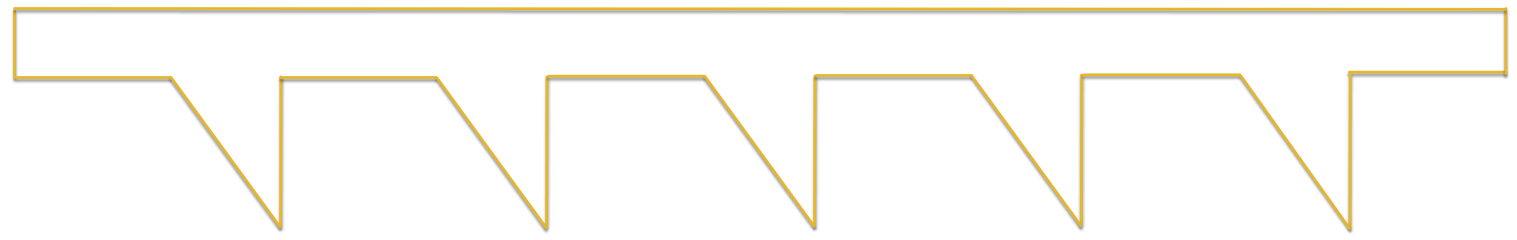

Figure 7. Composite rectangular and semi-triangular protrusions design of an AFRP laminate.

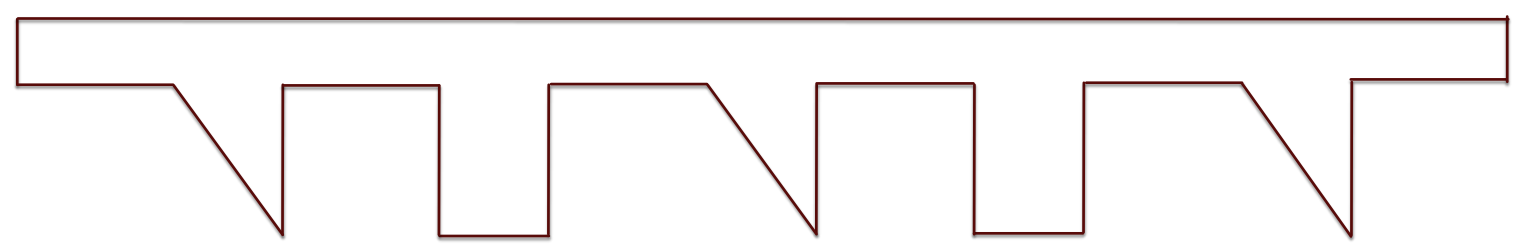

Figure 8. Composite squared and semi-triangular protrusions design of an AFRP laminate.

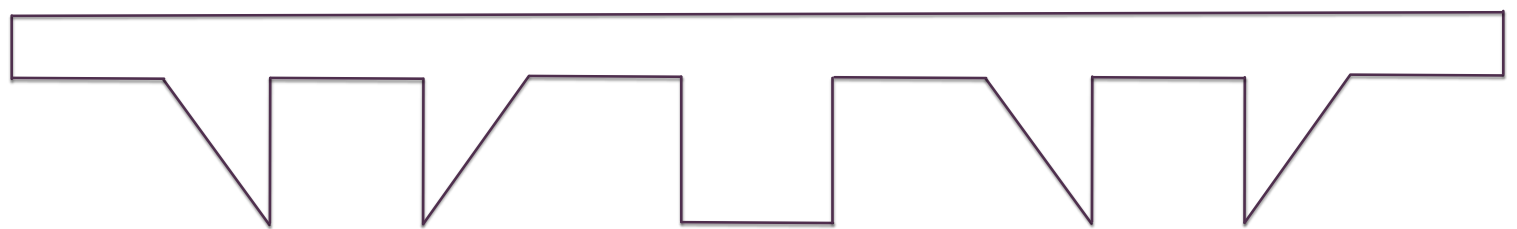

Figure 9. Continuous composite triangular and semi-triangular protrusions design of an AFRP laminate.

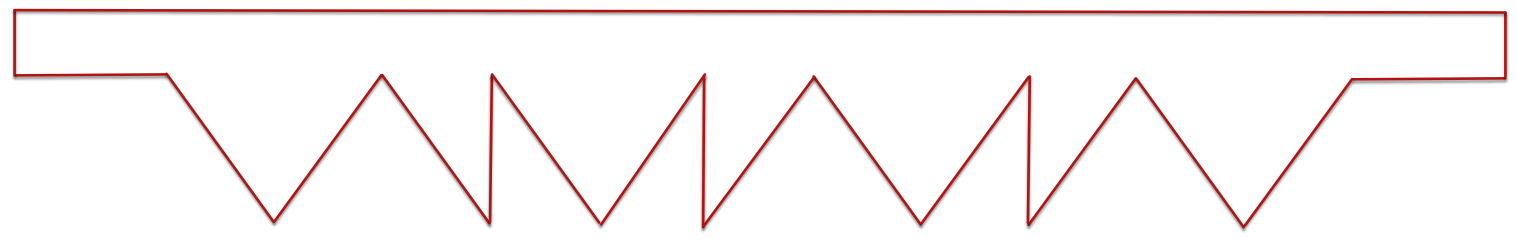

